\title{
DEMOCRACIA Y MEDIOS DE COMUNICACIÓN EN ESTADOS UNIDOS
}

\author{
DEMOCRACY AND THE MEDIA IN THE UNITED STATES
}

Leonardo A. Curzio-Gutiérrez ${ }^{1}$

\section{Resumen}

El sistema democrático de los Estados Unidos ha sufrido, desde hace ya varios años, una severa transformación en la cual los medios de comunicación desempeñan un papel primordial. La nueva realidad tecnológica ha quitado la centralidad en la articulación de la deliberación pública a los medios tradicionales: la televisión, la radio y la prensa. Hoy conviven con plataformas como Facebook, Twitter o Instagram que son accesibles a todos y que pueden formar redes independientes y hacer circular información, en múltiples sentidos, provocando una atomización de la conversación pública. En ese contexto, las posibilidades de los medios tradicionales de conducir el debate político se reducen, como se comprobó en las campañas del 2016 y lo vemos ahora de cara al proceso electoral del 2020. Con el triunfo de Donald Trump el término "fake news" adquirió una connotación de arma arrojadiza en contra de sus críticos y hoy es una de las principales amenazas a la integridad de la deliberación democrática. Por esta razón, es legítimo preguntarse si la apuesta de Trump por hostigar a los medios tradicionales es una amenaza para la integridad del sistema democrático o puede la democracia sobrevivir con una conversación polarizada y confrontacional, plagada de mentiras y manipulación de datos personales.

\section{Palabras Clave}

Democracia, medios de comunicación, deliberación pública, Estados Unidos, redes sociales.

\section{Abstract}

The democratic system of the United States has undergone, for several years now, a severe transformation in which the media play a major role. The new technological reality has removed the centrality in the articulation of public deliberation to the traditional media: television, radio and the press. Today they coexist with platforms such as Facebook, Twitter or Instagram that are accessible to all and that can form independent networks and circulate information, in multiple senses, causing an atomization of public conversation. In this context, the possibilities of the traditional media to conduct the political debate are reduced, as was verified in the 2016 campaigns and we see it now facing the 2020 electoral process. With the triumph of Donald Trump, the term "fake news" It acquired a thrown weapon connotation against its critics and today is one of the main threats to the integrity of democratic deliberation. For this reason, it is legitimate to ask whether Trump's bid to harass traditional media is a threat to the integrity of the democratic system or can democracy survive with a polarized and confrontational conversation, riddled with lies and manipulation of personal data.

\section{Key Words}

Democracy, media, public deliberation, United States, social networks.

\footnotetext{
${ }^{1}$ Universidad Nacional Autónoma de México. Correo electrónico: leonardocurzio@gmail.com.
} 


\section{Introducción}

Una visita a una librería especializada de cualquier capital latinoamericana o europea nos permitirá encontrar, entre las novedades bibliográficas, por los menos dos títulos que se preguntan si la democracia agoniza en Occidente (Levitsky y Ziblatt, 2018). Después del entusiasmo de la tercera ola democratizadora, que se extiende desde finales de la década de los 70 del siglo XX y que inició en Europa del Sur y después recorrió Europa del Este y América Latina, ahora tenemos un período de pesimismo muy marcado sobre la salud de los sistemas representativos. Lo característico de esta nueva etapa es que no solamente se percibe el riesgo de fractura de la democracia en países que vivieron una transición reciente y que ahora pueden ubicarse en la fase de consolidación, sino claramente en democracias consolidadas que propenden a formas de populismo que conviven de forma parasitaria con el sistema democrático (Urbinati, 2019).

No es nuestro propósito abordar en profundidad este debate, ni tampoco pronunciarnos sobre las posibilidades del sistema democrático liberal de sobrevivir a las tendencias actuales. En casi todos los países (Japón puede ser la excepción) que tienen un modelo democrático liberal, se detecta una crisis de representación de los partidos políticos tradicionales y una mayor desconfianza de los ciudadanos en las instituciones. Esta regresión de la confianza y la crisis de los partidos políticos tiene múltiples implicaciones. Una de ellas es que ha abierto la puerta a formas de organizar la deliberación pública fuera del ágora que eran los medios tradicionales, cosa que plantea desafíos inéditos. Nuestro propósito es reflexionar sobre el proceso político norteamericano y la transformación que ha tenido la relación entre el poder político institucional y los medios de comunicación y analizar si el fenómeno Donald Trump es un síntoma o la causa de esta descomposición. En las siguientes páginas estudiaremos la forma en que el presidente de los Estados Unidos ha alterado equilibrios importantes en la vida política norteamericana y el efecto que esto tiene en la fortaleza de la musculatura democrática.

\section{Planteamiento del problema}

\section{La democracia deliberativa y la formación de la opinión pública.}

Hay múltiples teorías de la democracia y diversas caracterizaciones de la misma. No es el propósito de este texto revisar las diferencias entre la democracia de los antiguos y la democracia moderna, como tampoco es nuestro afán glosar las características de una democracia representativa (Sartori, 2003). Damos por supuesto que un régimen democrático contempla dos grandes campos de actuación. El primero es garantizar la representación, lo más amplia posible, de una sociedad plural en sus distintos cuerpos de representación locales y nacionales y que, a partir de la voluntad de la mayoría, se otorgue un título de legitimidad a aquellos que ejercen la dirección de las instituciones. El segundo es garantizar el acceso a la información y la más extensa distribución de la misma, a fin de que los ciudadanos puedan tomar las decisiones que la propia democracia les exige. Una democracia tiene, en suma, cuando menos un componente procedimental y un segundo elemento de carácter deliberativo.

La base teórica del régimen democrático supone que el ciudadano elige a los cuerpos representativos que aprobarán las leyes y tomarán las decisiones que convengan al interés público. Para que este mecanismo funcione hace falta que la democracia tenga un componente deliberativo y, en consecuencia, siguiendo a Gutmann y Thompson (2004), es necesario que el soberano tenga acceso pleno a la información disponible y pueda leer, ver y escuchar, de manera abierta, interpretaciones diversas sobre las distintas opciones de política pública que tiene un país en un contexto determinado. La sociedad democrática requiere, igualmente, de un principio general de rendición de cuentas que obligue al poder público, en todos sus niveles y expresiones, a justificar sus decisiones con los argumentos técnicos o políticos que considere pertinentes, para dar una fundamentación jurídica coherente que explique que las decisiones del gobierno no contravienen al ordenamiento constitucional vigente en un país en un momento determinado o que tienen suficiencia presupuestal. Y finalmente, contrastar con la oposición política las razones que se esgrimen para sostener que la decisión adoptada es más conveniente que las propuestas formuladas por la minoría. Las democracias modernas y en particular la americana, requieren de una amplia deliberación de los actores institucionales y los partidos políticos que sea accesible a todos los ciudadanos sin censura o limitación alguna. Como lo estableció el juez Holmes en 1919, si a un grupo se le impide expresar sus ideas, el ciudadano se verá privado de todos los elementos que ofrece el (desde entonces) llamado "mercado de ideas", que es un pilar de la democracia, o como especificará años después el juez Cardozo: "es la condición indispensable de casi todas las demás libertades". 
En los Estados Unidos existe una sólida tradición jurídica que garantiza que, salvo en casos extremos (como una guerra o el esquivo concepto del peligro inminente "clear and present danger"), no puede limitarse la libertad de expresión sin generar una tensión con la primera enmienda de la constitución americana. El flujo de las opiniones debe ser libre e idealmente accesible para todo ciudadano.

Por accesible entendemos tres elementos diferentes:

1) El primero, muy valorado en democracias escandinavas, es el del lenguaje ciudadano (Plain language), que no es otra cosa que la posibilidad de que todo ciudadano, con independencia de su formación académica o sus conocimientos jurídicos, pueda tener una versión compacta, pero satisfactoria, de todo aquello que se discute en la arena pública por complejo y sofisticado que pueda parecer. En una democracia los ciudadanos son iguales a la hora de votar y se deben agotar todos los esfuerzos por garantizar que peculiaridades técnicas o jergas especializadas no alejen al ciudadano común de los debates más relevantes.

2) El segundo es garantizar que todos los elementos de información que apoyen la discusión pública estén disponibles para todos los ciudadanos y que la autoridad conciba que una democracia es el gobierno del pueblo, para el pueblo y por el pueblo; pero también frente al pueblo (Bobbio, 2013), dando así la oportunidad a todos los electores de poder comprobar la información, utilizar los datos abiertos, las bases de datos y todos los elementos técnicos que dan soporte a la información oficial. Además, todas las decisiones del gobierno, salvo las reservas especificadas en la ley, deben ser públicas. Una democracia puede tener secretos, pero éstos deben restringirse a la mínima expresión, es decir, seguridad nacional, la integridad de ciertos procesos delicados o datos personales.

3) El tercer elemento es que la información, las distintas posturas y las visiones alternativas de actores contrarios a la postura gubernamental, puedan ser distribuidas equitativamente por todos los canales disponibles, a fin de que todos los sectores de la sociedad puedan estar informados de lo que está en juego.

Ahora bien, puesto que una democracia deliberativa supone que todo mundo tiene derecho a participar en el gran debate nacional o como otros autores lo llaman, la gran conversación pública, es importante garantizar que el número de ciudadanos que participe en el debate público (y posteriormente participe en el proceso electoral), tenga un umbral mínimo que legitime colectivamente el proceso (Trejo Delarbre, 2015). Como ocurre con la participación electoral o su contrario el abstencionismo, no hay un parámetro predeterminado a partir del cual una tasa de participación en un proceso electoral deslegitime a una autoridad electa, pero es evidente que bajos rangos de participación minan la legitimidad de los poderes públicos. Los Estados Unidos tienen una larga y poco ejemplar tradición de baja participación por distintas razones que no es el caso de atender ahora. De manera similar, el número de ciudadanos que se allegan información y tienen una opinión contrastada y fundada sobre lo que está en juego, es deseable que sea mayoritario, aunque es sabido que en las democracias modernas buena parte de los ciudadanos no consume, por distintas razones, la cantidad y la calidad de información que se requeriría a un participante en un debate informado. Los ciudadanos, por decirlo así, son de pleno derecho, pero no de tiempo completo. En una democracia masiva, como las actuales, es imposible pedir al ciudadano que esté al día de todos los asuntos de la agenda pública y que tenga una opinión estructurada sobre las mismas. Es, sin embargo, una aspiración permanente de la democracia la formación de ciudadanos de alta intensidad.

De la misma manera, en una sociedad plural, debe asegurarse que todas las posturas o posiciones (que quepan en el arco constitucional) tengan la posibilidad de ser transmitidas al conjunto de los ciudadanos. El pluralismo, como principio, reconoce la discrepancia como un derecho válido y plantea que a través de la argumentación pueda cambiarse una decisión mayoritaria. Por tanto, discrepar, debatir y oponerse no solamente es éticamente válido, sino que es consustancial a una democracia. En consecuencia, el establecimiento de un régimen democrático supone la existencia de un espacio público para que florezca un debate enriquecedor (el ya mencionado mercado de las ideas de Holmes) en el que nadie pueda ser descalificado a priori. Los opositores al gobierno tienen el mismo derecho a hablar que el Presidente o la bancada mayoritaria en cualquiera de las dos Cámaras y el ciudadano tiene el derecho de oír a todos para contrastar opiniones y formular y reformular su criterio. La deliberación pública es dinámica y, por tanto, lo que hoy es aceptado por las mayorías, mañana podría dejar de serlo a la luz de informaciones novedosas o argumentos más persuasivos y eficaces o simplemente por un cambio del contexto. 
Una sociedad pluralista tiene, sin embargo, una frontera que los teóricos constitucionales han consignado de manera sistemática y es que todas las posturas tienen espacio en el debate democrático, salvo aquellas que atentan directamente contra los valores que son la base de la convivencia. Este tema no está zanjado y hay controversias constitucionales como la del juez Douglas en 1951 que alegaba que una ideología (el comunismo) no podía ser perseguida por citación judicial, por indeseable que pudiese parecer a la mayoría el contenido de esa doctrina o por ser contrario a los fundamentos de una democracia de mercado. El matiz, argumentaba el juez Douglas, estriba en que ni el prejuicio, ni el odio, ni siquiera el miedo insensato, deben motivar restricciones a la libertad de expresión, salvo cuando exista una prueba de daño inminente.

Un dilema similar surge cuando una ideología extremista y racista empieza a usar mentiras (fake news) para construir una conversación pública o una campaña electoral. Mentiras o medias verdades se han dicho siempre y la política, desde tiempos inmemoriales, ha recurrido a las mismas. George Bush invocó las armas de destrucción masiva para invadir Irak y ahora Trump busca legitimidad acusando a China de haber creado y diseminado el coronavirus. Nada nuevo bajo el sol. Pero el nuevo contexto tecnológico y comunicativo facilita el que una mentira pueda alterar la esencia misma de la democracia al introducir elementos falaces que crean divisiones artificiales o una polarización irreconciliable.

\section{El dilema Donald Trump: la mentira como recurso político}

Muchos observadores de la vida pública americana se han preguntado si elementos de la retórica de Trump y algunos de los grupos que lo han apoyado (algunos abiertamente racistas, otros con una marcada mentalidad anticientífica) deben ser tratados como los que emite un participante más del debate democrático. Es decir, si sus posturas políticas son aceptables como cualquier otra o bien, deben ser denunciados como los de un enemigo del pluralismo y la democracia. El dilema fue planteado en reiteradas ocasiones por Paul Krugman (2016) a lo largo de la campaña electoral del 2016. $\mathrm{Su}$ conclusión es que no todas las opiniones son respetables y válidas, algunas se fundan en evidentes mentiras. El argumento llevado al extremo por Krugman es si alguien plantea que la tierra es plana ise le debe considerar como una opinión más del mercado de las ideas o debe ser denunciada como falaz? Los medios serios, plantea Krugman como corolario de su razonamiento, deben denunciar la falsedad. Y de alguna manera es lo que hicieron. Buena parte de los diarios más influyentes de los Estados Unidos incorporaron (con visibilidad) la comprobación de datos y hechos ${ }^{1}$ a sus propuestas informativas, lo cual arrinconó a la retórica de Trump en la esquina de la demagogia populista y esa dinámica activó el ciclo de denuncia del presidente contra los medios tradicionales como sus enemigos políticos. No es casual que a muchos de ellos los mencionara en sus diatribas como uno de los pilares del establishment que había que derribar, como por lo demás lo hacen la mayoría de los gobiernos populistas de las Américas.

Dicho de otra manera, es discutible que, en nombre del pluralismo, pueda pedirse un espacio y un reconocimiento a quienes promueven ideologías totalitarias o racistas, como lo es también el de aquellos actores que utilizan el espacio democrático y al mismo tiempo optan por la violencia y el terrorismo. Los límites de la democracia son los linderos que evitan que los enemigos de la sociedad abierta se apoderen del espacio público para atentar contra ella. Ese es el principal dilema de la integridad del sistema democrático en los Estados Unidos.

La deliberación pública supone la existencia de un régimen clásico de libertades que garantiza la libre expresión y también la libre circulación de las ideas, porque esto permite articular el razonamiento público (Drèze y Sen, 2013, p. 271 y 55). Es crucial constatar que, en una democracia moderna, con tantas conexiones como las que permiten las modernas tecnologías, el debate público no se da de una manera (permítaseme la licencia) químicamente pura. No todos los participantes en el debate están motivados por una visión ideal de lo que significa el interés público. Hay interferencias que deben ser identificadas y apropiadamente matizadas. La primera es el debate ideológico propiamente dicho. A diferencia del lenguaje científico o académico, el discurso político no se guía por la búsqueda de la verdad y la objetividad, persigue más bien la legitimación de los propios postulados para maximizar la propia posición. Otro factor que puede alterar la deliberación pública es el interés económico de grupos (empezando por los propios medios de comunicación) que pretenden influir en el debate público, en muchas ocasiones, con más recursos que los propios actores institucionales para presentar una versión determinada de algunos temas. Y finalmente, podemos tener mentiras puras y duras motivadas por distintos actores que puedan, como veremos más adelante, tener una aspiración política o una incidencia en el debate público, como pueden ser candidatos antisistema, iglesias o ciertos grupos de interés.

${ }^{2}$ El sitio Politifact.com estableció un barómetro sobre la veracidad de las declaraciones de Trump e incluso revisó su discurso de toma de posesión el día 8 de noviembre del 2016. 
Conviene, a estas alturas, traer a colación otro concepto: la agenda pública. Esta se toma por el conjunto de temas que en un contexto determinado se consideran prioritarios para el funcionamiento y la organización de un país. La agenda pública se puede integrar por un número indeterminado de temas, pero la capacidad de las sociedades para procesarlos es limitada; en consecuencia, los componentes que la integran suelen ser dos o tres. La disputa por la atención colectiva supone un proceso que en inglés llaman agenda setting (Protess y Mc Combs,1991) que no es otra cosa que la capacidad de determinar que un tema es de interés nacional y, en consecuencia, merece un escrutinio colectivo cotidiano y sistemático.

No es cuestión de profundizar tampoco en estas páginas en la forma en que se integra la agenda pública y los actores que pugnan para articularla. Baste, para proseguir con nuestra argumentación, con el reconocimiento de que, si en el modelo clásico de finales del siglo XX, de una democracia deliberativa, el gobierno, los partidos políticos y los medios de comunicación tenían un papel protagónico, hoy la nueva realidad tecnológica ha venido a trastocar este supuesto. El gobierno conserva una enorme capacidad de fijar temas en la agenda pública a través de los mecanismos tradicionales o la (seguida por millones) cuenta de Twitter de Trump. Las fuerzas políticas tradicionales conservan también mil canales para subir a la atención nacional los asuntos que consideren apropiados. Ahora bien, lo que es palmario y visible en los Estados Unidos y en muchos otros países, es que la nueva realidad tecnológica ha quitado a los medios tradicionales la función heliocéntrica que antes tenían, para convertirlos en un planeta más. No cabe duda de que son los planetas mayores, particularmente la televisión, la radio y la llamada prensa seria, pero hoy conviven con plataformas como Facebook, Twitter o Instagram que son accesibles a todos y que pueden formar redes con independencia de los grandes canales tradicionales y hacer circular información, en múltiples sentidos, provocando una atomización de la agenda, fenómeno de creciente interés entre los estudiosos de la comunicación.

La atomización de la agenda pública es una consecuencia directa de esta nueva realidad en la que los distintos intereses de una sociedad plural encuentran un camino de expresión directo y ampliamente satisfactorio. Todo ciudadano, con un dispositivo con acceso a Internet y una cámara, puede subir contenidos a la red. Por supuesto, algunos correrán con mayor o menor aceptación por parte de otros participantes de la red y eso le dará, a esos contenidos, una forma de validación muy diferente a la de los medios de comunicación tradicionales. En los nuevos canales, el número de likes, corazones de aceptación, muestras de aprobación por reproducciones de comentarios, tweets o videos, se convierte en un elemento más importante que el escrúpulo tradicional de los medios de divulgar información atractiva, pero siempre cuidando la línea general de lo que se llama el rigor periodístico. Es evidente que las fronteras de dicho rigor no son rígidas, pero en términos generales, puede decirse que en los medios tradicionales la verificación de fuentes y la verosimilitud de la historia que se presenta a las audiencias se da por supuesta, porque el sello editorial lo respalda ${ }^{2}$. En los nuevos medios, como veremos más adelante, puede publicarse cualquier cosa sin que nadie se haga responsable del contenido.

En las redes sociales toda opinión puede expresarse sin ninguna consecuencia. Casi cualquier comentario racista o peyorativo puede integrarse a la pared del Facebook. Prácticamente cualquier usuario de Twitter puede arrojar insultos y descalificaciones con pocas cortapisas a sus adversarios. Si en el modelo tradicional la deliberación pública tenía como límite el respeto a los valores constitucionales, en el periodismo tradicional la búsqueda de la verdad era la estrella polar, en las redes sociales lo que menos importa es el rigor y casi cualquier contenido puede ser subido a la red sin que, hasta el momento, se haya encontrado ningún mecanismo para distinguir lo que es una historia verdadera o un dato incontrastable, de aquello que es mentira o números sin ninguna solidez metodológica. En la red se puede decir lo que uno quiera sin que haya mecanismos correctivos ni responsabilidad asignada a una casa editorial o a una cadena televisiva. Es un mercado en el que igual da el gato que la liebre. Trump hizo campaña con el Twitter y, desde esa red, desafió el conocimiento convencional de la elite republicana y conectó con un electorado radicalizado que no había aceptado con todas sus consecuencias el triunfo de un presidente afroamericano, Barak Obama, en 2008 y los efectos devastadores de la crisis y la nueva revolución tecnológica.

De esta forma, el ciudadano contemporáneo y particularmente los más jóvenes, se encuentran con una digitalización de la conversación pública que circula sin demasiados controles de veracidad en un universo que ha dado en llamarse multimedia, que no es otra cosa que contenido noticioso que circula por varios soportes de comunicación combinados (texto, foto, o video) y se distribuye por distintos canales. Se perfila como tendencia general que la imagen predomine, como lo advirtió Sartori en el célebre ensayo sobre el homo videns (Sartori, 1998 y 2003). Las imágenes se canalizan mejor

\footnotetext{
${ }^{3}$ En su número del 3 de abril del 2017 la revista TIME sugería en su portada una polémica pregunta: Is truth dead?
} 
que las ideas complejas y la construcción de una razón pública basada en argumentos. Las democracias dominadas por la televisión mostraron patologías que autores como Popper (1998), al final de su vida, analizaron con preocupación, pero las democracias con Internet nos están dando una nueva realidad que plantea, en la misma proporción, oportunidades y desafíos (Neuman, Bimber y Hindman, 2011).

Las oportunidades de subvertir un orden determinado y el dominio abrumador de los medios tradicionales son viables por la posibilidad que hoy tienen las sociedades de tener una comunicación horizontal (con video incluido) que puede llegar a ser viral y que es muy difícil que un gobierno cancele o límite (Fogel y Patiño, 2007). Hoy en día, la represión gubernamental puede ser exhibida en la red y convertirse en un arma poderosa en contra de impulsos autoritarios de cualquier gobierno. Buena parte de las revueltas liberadoras, desde Moldavia hasta las del mundo árabe, son producto de esta nueva realidad tecnológica. No nos detendremos demasiado en esto, que ha sido analizado por Manuel Castells (2012) y no porque no sea importante, sino porque nos desvía de nuestro objeto de estudio principal que son las elecciones americanas.

En el proceso electoral del 2016 pudimos constatar el uso masivo de los medios alternativos para diseminar mentiras (algunos las llamaban pomposamente verdades alternativas) con un propósito político deliberado de desacreditar e incluso la difusión de falsedades con una innegable vocación de estigmatizar a ciertos grupos. Como ha apuntado Joshua Benton (2016) de Nieman Lab, en un pequeño pueblo del sur de Luisiana, por ejemplo, la víspera de la elección aparecieron, en la página del Facebook del alcalde en funciones, historias que no tenían fundamento. Algunas de estas volvían sobre temas tan disparatados como el hecho de que Hillary Clinton llamaría a una guerra civil en caso de que el candidato republicano fuera electo, tratando de minar, de esa manera, su compromiso democrático y reforzando la idea de que Trump en realidad era un candidato genuinamente antisistema, una auténtica amenaza contra el sistema político que generaba creciente irritación en amplios círculos de la población.

Otra historia difundida por esa vía fue aquella que le dio la vuelta al mundo por su falsedad, según la cual el papa Francisco había decidido apoyar a Trump. Miles de personas vieron esa información sin que atendieran posteriormente al desmentido. Muchas de ellas votaron pensando que el Papa, efectivamente, había apoyado a Trump. El tema es que las nuevas tecnologías permiten direccionar esos mensajes a grupos predispuestos a escucharlos favorablemente, pues refuerzan sus convicciones y prejuicios.

Las historias sin ningún tipo de fundamento podían reproducirse en miles de páginas y, a través de la interacción, ganar credibilidad. Algunas eran francamente burdas como el hecho de que Obama había admitido finalmente que había nacido en Kenia y otras eran más sutiles y venenosas, como aquella que sugería que el agente del FBI que había filtrado información sobre la corrupción de Hillary Clinton había aparecido muerto.

Los controles crecientes (de los medios de comunicación) sobre la veracidad de la información son difícilmente aplicables en un universo como Internet, que nació libre y muy probablemente lo siga siendo con los beneficios y problemas que esto plantea. La información generada en páginas web (y reproducida por audiencias predispuestas a creer en ellas) fomenta las teorías de la conspiración, forma de pensamiento altamente compatible a la ideología extrema de grupos radicalizados. Todo es culpa de un pequeño grupo que atenta contra el pueblo bueno y engalanado de todas las virtudes cívicas. Para Facebook, por ejemplo, este tipo de casos implican una nueva responsabilidad (nada sencilla de cumplir) para etiquetar páginas de amplia difusión o con una interacción importante, si la información que publican es falsa. Para Twitter, la relación con uno de sus usuarios más activos es hoy motivo de polémica. Todo esto está todavía por desarrollarse.

De manera exponencial ese amasijo de información falsa, opiniones y prejuicios se fue convirtiendo en una tendencia en las redes sociales que se distribuyó en páginas de Facebook y cuentas de otras redes que conectan al Tea Party con el Ku Kux KLAN, por citar solamente dos casos. El encuentro en la red y la reconfortante sensación (todos las sentimos cuando alguien refleja en el espacio público nuestros anhelos y nuestras frustraciones) de tener una comunidad de sentimientos (y prejuicios) con un número amplio de ciudadanos que cada vez se auto limita menos para expresarse.

Esta situación fue envalentonando a estos grupos para salir de la periferia del sistema y afirmar, sin ambages, que no se avergonzaban de su ideología racista, nativista y anticientífica. Por primera vez, desde que la corrección política se instaló como norma en los medios de comunicación tradicionales y en la élite política profesional, un candidato se 
atrevía a exteriorizar de forma directa. Incluso llegó a utilizar un lenguaje machista y procaz para dirigirse a mujeres y a integrantes de otras comunidades. Trump hablaba cómo ese sector quería que hablase y sin que pruritos constitucionales o científicos lo limitasen, Trump podía negar la americanidad del juez Curiel (por tener origen mexicano) o la inexorabilidad del cambio climático por efecto de la actividad humana y eso reconfortaba a los radicales que recibían mensajes confirmatorios de todas esas falsedades.

Esos grupos, que antes se sentían en la periferia del sistema, consiguieron sus propios medios y un paladín que decidiera hablar como ellos. Y esos contenidos falaces y mendaces empezaban a circular por ese territorio que algunos tratadistas han llamado "transmedia" que no es otra cosa que: "un proceso narrativo basado en el fraccionamiento del contenido y su diseminación a través de múltiples plataformas, soportes y canales (offline y online), con el fin de que cada medio pueda contar una parte específica y complementaria de la historia" (Rivera, 2012).

Los propios medios tradicionales incorporaron las mentiras y los prejuicios a su agenda informativa cotidiana, algunas veces para desarrollarlos y otras, para criticarlos. La pregunta de todas las mesas editoriales era la pertinencia de considerar cualquier opinión como válida y consignarla acríticamente. Por ejemplo, los mexicanos son los responsables de los elevados niveles de criminalidad. ¿La misión de los periodistas profesionales era demostrar su origen propagandístico y segregador? ¿ O simplemente referirla y atribuirla? En otras palabras, ¿si algún personaje decidía defender la creación divina en contra del evolucionismo, debería considerarse como una dualidad verdad/mentira o una opinión tan respetable como cualquier otra? El dilema no es menor, porque muchos grupos intransigentes y abiertamente racistas, pretenden hacer pasar sus posturas como si fueran una opinión más en el universo plural de una democracia deliberativa. La campaña de Trump puso a los medios de comunicación frente a uno de los dilemas más importantes de su historia y Trump se encargó de ubicarlos como sus enemigos frontales, los enemigos del pueblo.

La atomización de la agenda ha permitido, en efecto, a grupos minoritarios reafirmar su sentido de pertenencia y poder disponer de canales de comunicación que reafirmen su identidad (Rubio, 2017). Esta atomización ha permitido que los grupos de interés que uno pueda imaginar, desde informativos hasta de entretenimiento, hoy encuentren modo de relacionarse con audiencias o colectivos que tienen exactamente los mismos intereses y que en muchos casos comparten las mismas opiniones. Es una extraña paradoja que la Internet, que estaba llamada a conectar el mundo cada vez con mayor eficiencia esté, al mismo tiempo, desarrollando cada vez con mayor nitidez grupos cerrados que dialogan entre ellos y son refractarios a una deliberación amplia, en la cual puedan escucharse los puntos de vista que desafían el propio.

\section{La democracia americana amenazada: mentira y desconfianza}

Ese fundamento de la democracia que apuntábamos antes, la posibilidad de acceder al mercado de las ideas hoy parece amenazado por esta proliferación de islas inconexas que discuten y se retroalimentan entre ellas sin tomar en cuenta referentes externos que contradigan, maticen o pongan en entredicho las propias concepciones. Ya un filósofo alemán (Peter Sloterdijk) lo había notado en el contexto de las democracias europeas y lo había llamado "la conformidad acústica". Esta conformidad significa algo tan sencillo como que a algunos ciudadanos les agrada escuchar información y opiniones que refuercen el propio punto de vista y tienden a sentirse incómodos o desafiados cuando escuchan, leen o ven información que contradice algo en lo que ellos creen. La conformidad acústica ha dado paso a un término que ha ganado fortuna y que, de alguna manera, sintetiza esa proclividad a rechazar aquello que nos resulta desafiante o contradice una serie de posturas ideológicas y políticas que se asumen e interiorizan. Se trata de la "posverdad" que se define como la "distorsión deliberada de una realidad, que manipula creencias y emociones con el fin de influir en la opinión pública y en actitudes sociales” (Real Academia Española, 2017).

En un universo de medios competitivos puede encontrarse un equilibrio al garantizar que en los principales canales de televisión y radiodifusión se permita que todas las voces del abanico constitucional puedan expresarse. De esa manera, ciertamente imperfecta, se fomenta que un ciudadano que tenga sesgos y preferencias, pueda escuchar información de otros actores políticos o con otra orientación ideológica e idealmente ponderarla, valorarla e incluso admitirla. En las redes es menos probable que esto ocurra, porque se rigen por un principio de afinidades electivas y eso potencia que el diálogo se dé entre convencidos. Yo solo hablo con los de mi tribu. Por tal razón, el debate tiende a ser cada vez más insular y segmentado, lo cual plantea un desafío colosal para una sociedad como la norteamericana que tiene prácticamente un acceso universal a una Internet de buena calidad. 
En ese contexto de atomización de la agenda pública, las posibilidades de los medios tradicionales de conducir el debate político se reducen notablemente, como lo pudimos comprobar en las campañas del 2016 y lo vemos ahora de cara al proceso electoral del 2020. Como bien lo expresó en uno de sus editoriales el The Washington Post (2016), si por ellos hubiese sido, Trump no hubiera sido ni siquiera candidato del partido republicano, mucho menos presidente de los Estados Unidos. Pero ganó y eso obliga a replantear algunos supuestos. Para la prensa escrita, la elección de Trump marca un antes y un después en su capacidad de influir en la opinión pública. La pérdida de centralidad de los medios de comunicación tradicionales se combinó con un retroceso de la credibilidad en los mismos que distintas encuestas consiguieron detectar. Así lo muestra el estudio de Edelman (2019), el cual indica que la confianza en los medios de comunicación cayó para ubicarse en niveles de $47 \%$.

Figura 1: La confianza en dos instituciones (medios y gobierno).

\section{A MODEST RISE IN TRUST}

Percent trust

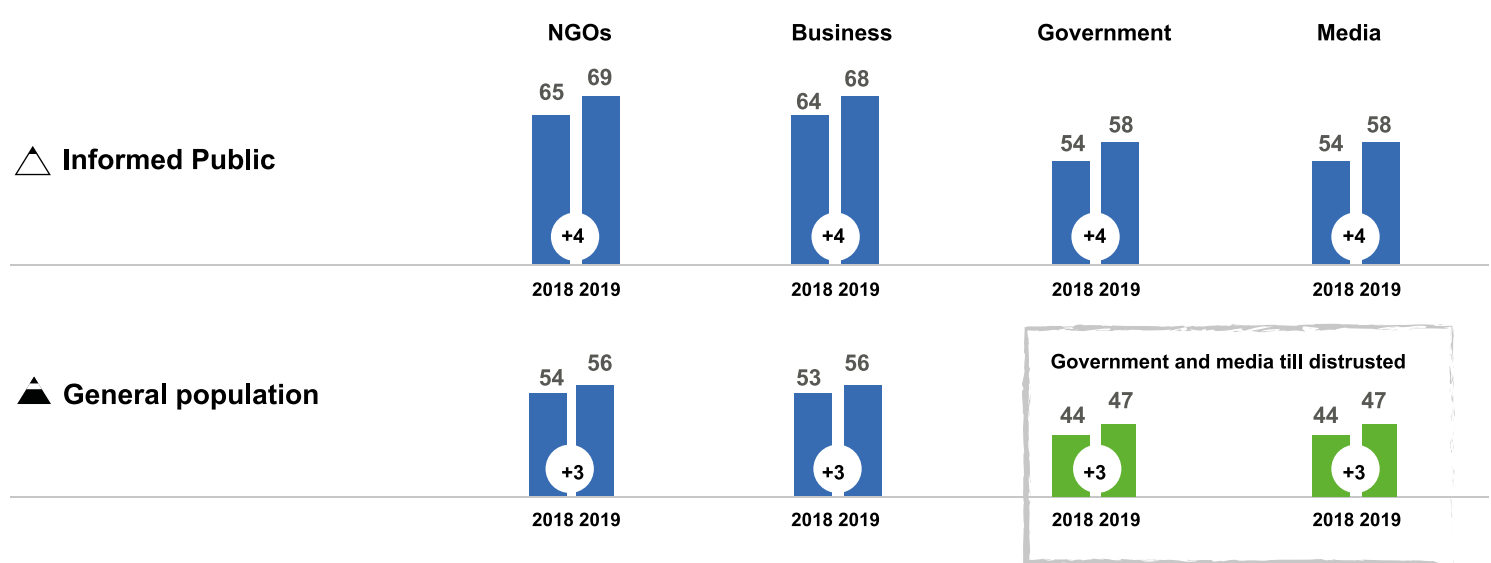

Fuente: TRUST BAROMETER. Global Report 2019. Edelman.

Cuando el precandidato Donald Trump se refería al establishment al que había que derrotar, incluía invariablemente a los medios de comunicación a los que, de manera sistemática, sigue utilizando como presidente de los Estados Unidos como su némesis. Para algunos conservadores esa línea de argumentación ha permitido al presidente consolidar su discurso como el de un patriota que lucha contra el pantano de los intereses creados (Rose, 2018). Pero al mismo tiempo, como lo subraya en un reciente libro James Poniewozik (2018), la esencia del Presidente se formó primero en las revistas como el magnate heterodoxo, una celebridad provocadora y contrastante y después pasó a televisión en el papel estelar del programa The apprentice. Hoy el aprendiz ha pasado a ser el verdugo.

Ganó la presidencia confrontando al verdadero americano con los globalistas, con aquellos cuyo origen no era nítido, los que requieren un gentilicio previo (mexicanos, asiáticos, afros, etc.) para tener carta reconocida. Por eso la política de la identidad ha jugado un papel central en estos tiempos, una política riesgosa y segregadora en el largo plazo (Fukuyama, 2018). Una suerte de ciudadanos de segunda que, aliados con una élite desaprensiva, roban el alma a la nación. Por eso su lema de "America first" fue tan potente. Conecta con ese sentimiento de abandono, identificado ya desde hace varias décadas por Huntington, de los "genuinos" americanos, los que representan la identidad frente a los globalizadores desnaturalizados. En la ONU, el propio Trump (septiembre, 2019) dijo que el futuro pertenecía a los patriotas no a los globalistas.

Como todos los populistas, Trump asume que el pueblo es él y desde esa posición despliega su estrategia victimista. En una entrevista de mayo del 2020 con la cadena FOX afirmó que desde Lincoln ningún presidente había sido peor tratado que él por los medios tradicionales, el argumento no era novedoso, ya lo había citado en su cuenta de Twitter (@realDonaldTrump, enero 2020). Se presenta siempre que puede como el incomprendido. Sus invectivas contra los medios de comunicación como el NYT y CNN son frecuentes. Los reagrupa bajo la etiqueta de "fakenews lamestream 
media”. Trump alega que ese y otros canales de TV se negaban a publicar los avances de su gobierno, que en otras palabras significa que no informan lo que él quería. El presidente, tratando de imponer líneas editoriales a los medios o en querella cotidiana contra ellos es una amenaza directa a la integridad de la democracia americana.

\section{Una sociedad dividida y crecientemente polarizada}

En los últimos años se ha popularizado, en el análisis político, la idea de una América dividida en dos grandes mitades y de que su democracia enfrenta riesgos. Los títulos de las novedades editoriales son sintomáticos. Desde el elegante ensayo de Greenblat (2018) sobre Shakespeare, hasta obras especializadas que hablan de cómo salvar una democracia constitucional (Ginsburg and Aziz, 2018) pasando por ensayos que versan sobre las políticas del resentimiento (Cramer, 2016), la petulancia (Wolfe, 2018) y el discurso del odio (Taibbi, 2019). El fantasma del autoritarismo recorre América.

La América dividida en dos partes casi idénticas fue evidente en el proceso electoral del 2016. Sin embargo, podemos afirmar que en realidad esta división ha sido una constante (con algunas variaciones) a lo largo del siglo XX. Si analizamos, con cierto detenimiento, los resultados electorales de los comicios que han tenido lugar en esta centuria, podemos constatar que existen dos hemisferios de proporciones similares que han variado en las sucesivas convocatorias electorales. Por ejemplo, en el 2000, George Bush alcanzó 50.456.000 votos, mientras que Al Gore obtuvo 50.996.000 sufragios. El siglo se inaugura con la paradoja de que el ganador del voto popular no era el triunfador en el colegio electoral, como ocurriría 16 años después con el triunfo de Donald Trump. Pero empezamos el siglo XXI con una América partida en dos mitades casi perfectas, lo cual no tendría nada de particular dada la naturaleza del sistema electoral norteamericano que fomenta este tipo de comportamiento, si no estuviésemos también ante dos formas de entender el mundo que se repelen de forma creciente. Estas dos maneras de concebir los desafíos de los Estados Unidos en la propia realidad nacional y su la proyección internacional, llegarán muy pronto a una bifurcación de las narrativas nacionales. Un momento clave se dio cuando el gobierno de George Bush decidió usar una serie de argumentos mendaces y dicotómicos, con ellos justificar una intervención imperial en Irak (Singer, 2015). La forma en que el entonces gobierno republicano utilizó la dicotomía amigo-enemigo, es decir, estás conmigo o contra mí, sin matices o mediaciones posibles, acentuaba de manera casi apocalíptica la irreconciliable partición.

Tabla 1: Resultados electorales 2000-2016

\begin{tabular}{|c|c|c|c|}
\hline & & ELECTORAL & POPULAR \\
\hline \multirow[t]{2}{*}{2000} & George W. Bush & 271 & $50,456,062$ \\
\hline & Albert Gore, Jr. & 266 & $50,996,582$ \\
\hline \multirow{2}{*}{2004} & George W. Bush & 286 & $62,039,073$ \\
\hline & John F. Kerry & 251 & $59,027,478$ \\
\hline \multirow{2}{*}{2008} & Barack H. Obama & 365 & $69,456,897$ \\
\hline & John S. McCain & 173 & $59,934,814$ \\
\hline \multirow{2}{*}{2012} & Barack H. Obama & 332 & $65,446,032$ \\
\hline & W. Mitt Romney & 206 & $60,589,084$ \\
\hline \multirow{2}{*}{2016} & Donald J. Trump & 304 & $62,980,160$ \\
\hline & Hillary R. Clinton & 227 & $65,845,063$ \\
\hline
\end{tabular}

Fuente: Historical Presidential Elections. 270 to Win.

En el 2004 cambiaron un poco las cosas y la victoria de Bush fue más holgada, pero la división se mantenía. El polémico presidente obtendría 62 millones de votos y John Kerry, el candidato demócrata superaba ligeramente los 59 millones.

Si los números dejan ver con claridad esta sociedad de dos mitades, la cartografía electoral nos refleja también una América azul en las costas y una América roja en el centro que persiste (con algunas variaciones) hasta las elecciones del 2016. Como podemos ver en los sucesivos mapas y sus coloraciones, hay dos realidades sociológicas y políticas que estructuralmente parecen incompatibles en los Estados Unidos. 
Figura 2: Votos electorales por Estados. Elección presidencial año 2000.

\section{Presidential Election Interactive Map}

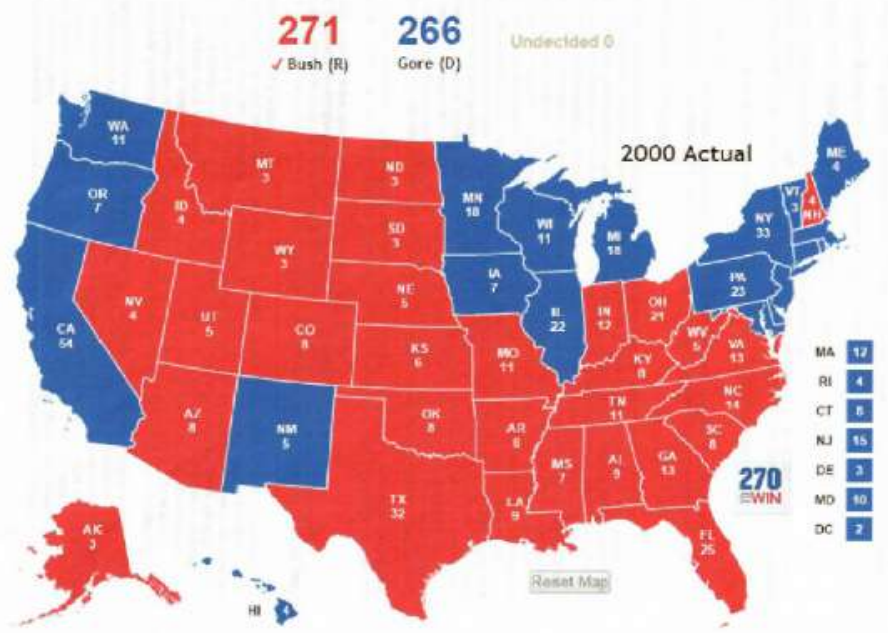

Fuente: Historical Presidential Elections. 270 to Win

Figura 3: Votos electorales por Estados. Elección presidencial año 2004.

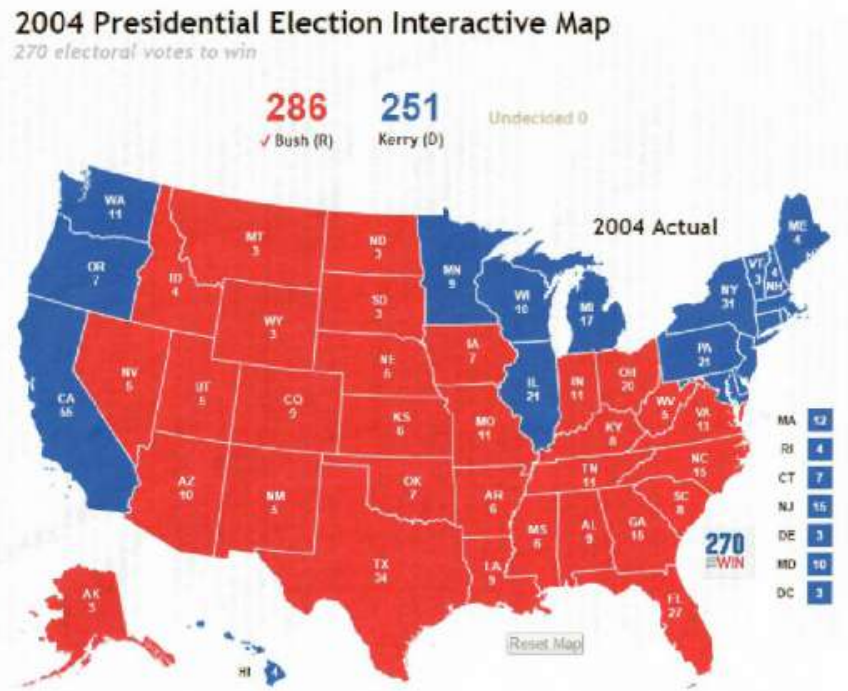

Fuente: Historical Presidential Elections. 270 to Win

Figura 4: Votos electorales por Estados. Elección presidencial año 2008.

2008 Presidential Election Interactive Map

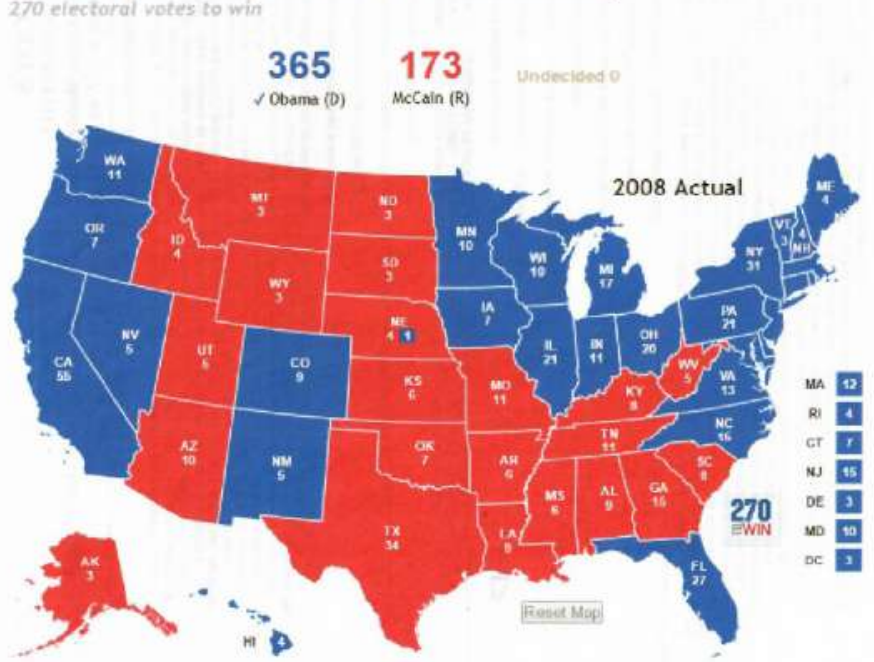

Fuente: Historical Presidential Elections. 270 to Win. 
En el 2008, el péndulo cambia de sentido y Barack Obama consigue una abrumadora victoria sobre el senador de Arizona, John McCain. La distancia es de 10 millones de votos y el triunfador Obama decía que el mandato que le daban las urnas, implicaba una revitalización del llamado sueño norteamericano y superar las divisiones. No se logró ninguno de los dos. Los cerca de 60 millones de ciudadanos que votaron por McCain se sintieron desplazados y descolocados en una América en la que no se reconocían, ni por la pigmentación de la piel de su presidente, ni por sus políticas de protección a los más necesitados. Esa América blanca que cree que el gobierno no debe extender su brazo protector a temas tan sensibles como la salud, argumentaba que un "comunista no nacido en los Estados Unidos" estaba usurpando la primera magistratura. Una buena parte de la narrativa desplegada por los políticos republicanos y sus medios afines consistía en negar la americanidad del presidente. Una encendida polémica sobre el lugar de nacimiento de Obama consumió, durante años, a un sector del electorado que sin pruebas y aún contra de ellas, decidió que el presidente afroamericano no era un integrante de su comunidad. Él no es como nosotros. Necesitamos a alguien que nos represente y ese alguien fue a la postre Trump.

Esos 60 millones de votantes de los estados del centro del país vivieron la administración Obama como una especie de amenaza existencial. El cambio demográfico que implicaba el que algunas minorías (como los hispanos) pudiesen determinar quién iba a ser en última instancia el inquilino de La Casa Blanca, resultó perturbador para ellos. La idea ya muy difundida entonces del declive relativo de los Estados Unidos respecto a potencias en ascenso (China), conjugada con la percepción de pérdida de influencia política electoral de los blancos respecto a los afroamericanos y a los hispanos y otras minorías, adquirió proporciones colosales. Este conjunto de factores fue prefigurando el ambiente en el cual un personaje como Donald Trump cosechara la victoria.

En las elecciones del 2012 las distancias entre republicanos y demócratas se vuelven a recortar. Volvemos a encontrar dos mitades del voto popular casi perfectas. Mitt Romney alcanza 60.600.000 votos y Barack Obama gana con 65.450.000 votos en números redondos. Nuevamente la geografía electoral nos permite ver que las costas permanecían sólidamente leales a los demócratas y el centro del país permanecía sólida y pertinazmente favorable a los republicanos, sólo que cada vez más radicalizados.

Figura 5: Votos electorales por Estados. Elección presidencial año 2012.

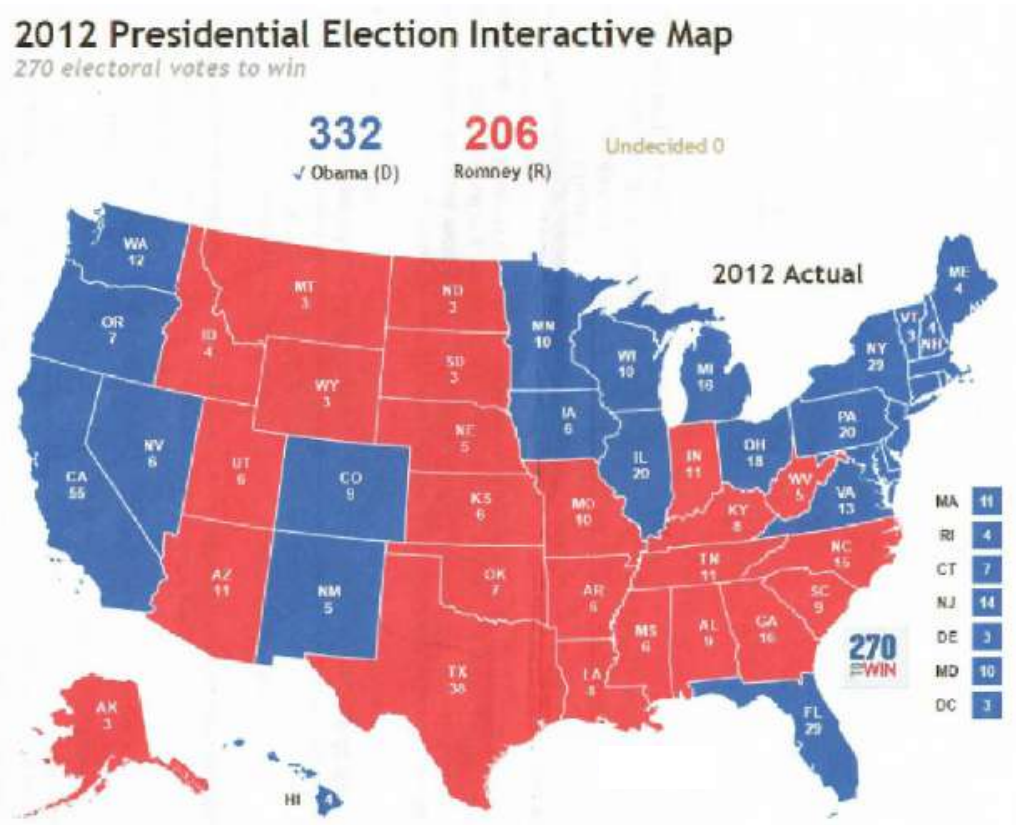

Fuente: Historical Presidential Elections. 270 to Win.

Para hacer más complejo el panorama, los estudios de opinión del Pew Research Center y de otras casas encuestadoras, nos permitieron constatar que la participación de los radicales de cada una de las corrientes políticas era creciente. Cuando Barack Obama y los republicanos se enfrentan sobre distintos asuntos de la agenda nacional, las posiciones de los republicanos tendían a concentrarse en enfoques crecientemente conservadores, dejando atrás las posturas centristas y las posibilidades de compromisos bipartidistas que habían marcado la política americana de la postguerra.

En los dos principales partidos, el número de centristas ha tendido a reducirse en los últimos 20 años en favor de 
visiones consistentemente liberales e incluso francamente críticas entre los demócratas (que explica el ascenso de Bernie Sanders). Y de manera recíproca, entre los republicanos creció el número de conservadores que encontraron en Trump su portavoz y paladín. El corrimiento a los extremos se aprecia en las siguientes distribuciones de 1994 a 2017.

Figura 6: Polarización política entre los americanos

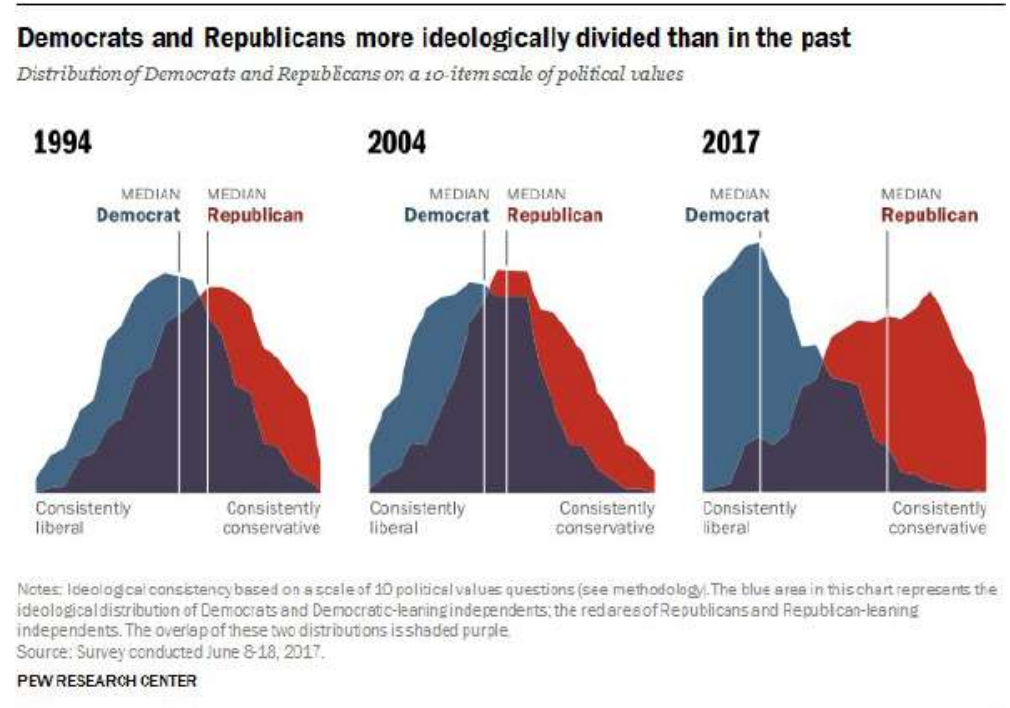

Fuente: Pew Research Center, October, 2017, “The Partisan Divide on Political Values Grows Even Wider”.

Lo que vendría en 2016 es una consecuencia natural de esta estructura sociológica del voto. Después de ocho años de gobiernos demócratas, el péndulo giraba a la derecha y Donald Trump ganaba la elección en el colegio electoral con 304 votos y con un respaldo de cerca de 63 millones de votos populares, mientras que Hillary Clinton no consiguió rebasar los 65 millones que tuvo Obama en su reelección y a pesar de su triunfo en el voto popular, no pudo retener dos estados (Michigan y Wisconsin) tradicionalmente azules.

Figura 7: Polarización política entre los americanos

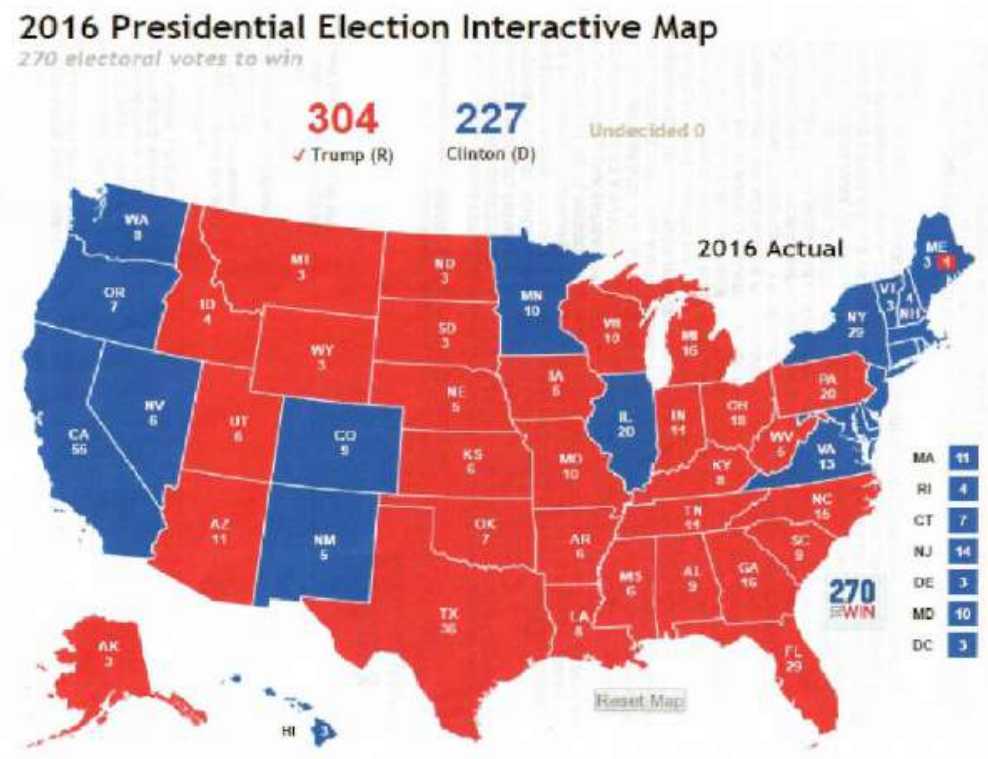

Fuente: Historical Presidential Elections. 270 to Win.

\section{La era de la desconfianza}

Pese a la enorme división y polarización que hemos constatado, los americanos siguen teniendo una visión positiva de su futuro. Según otra encuesta del Pew Research Center, el nivel de confianza de los norteamericanos en el futuro de su país se mantiene en niveles altos. Alrededor del $71 \%$ de los ciudadanos dice tener bastante confianza en el porvenir, mientras 
que el número de personas que se muestra pesimista respecto a lo que viene, representa el $28 \%$. El problema es que el optimismo se liga a una visión cada vez más radical: el futuro será mejor si se suprimen los privilegios de minorías o se construye un muro. Por supuesto que estos números requieren de una lectura contextualizada para evaluar cómo han cambiado en este siglo. Si consideramos que en el 2015 el número de americanos que se mostraba poco animado con el futuro ascendía a 15\%, en 2017 ese número se duplicó. Podemos asociar con las campañas una sensación de zozobra sobre el porvenir, pero eso no lo explica todo. Por supuesto, en Estados Unidos, como en casi todas las democracias, la lectura partidista cambia la función de los resultados electorales y quien ocupa el gobierno. En 2013, por ejemplo, el número de republicanos que se decía frustrado por el futuro del país alcanzó niveles inusualmente altos, como vemos en la gráfica sobre las actitudes de los americanos hacia el gobierno.

Figura 8: Opiniones y sentimientos respecto al gobierno.

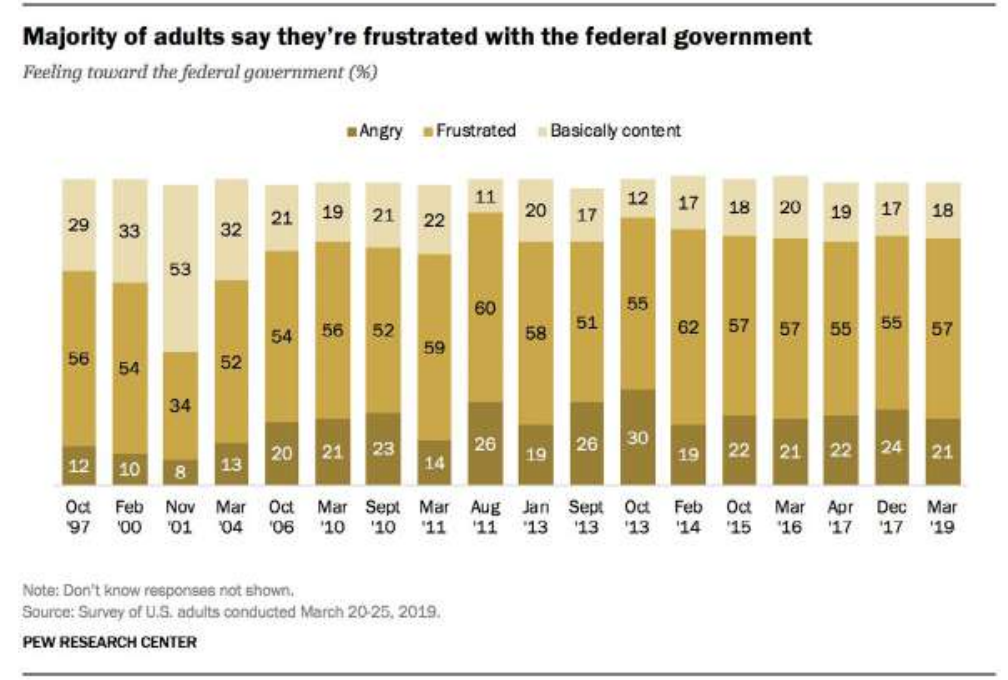

Fuente: Pew Research Center, April, 2019, "Little Public Support for Reductions in Federal Spending”

Si vemos con detenimiento los números contenidos en la gráfica 8 , veremos qué si bien la distribución no ha cambiado demasiado en los últimos cinco años, la insatisfacción por el gobierno en turno se ha mantenido en niveles similares hasta marzo del 2019; la única excepción fue noviembre del 2001 cuando después de los ataques terroristas, 53\% los americanos se sentían muy satisfechos con la acción gubernamental. Hacia 2004, cuando se dio la reelección de George W. Bush, el número de satisfechos se había encogido en un 20\% y el número de frustrados se había incrementado en una proporción similar, pero en esos años el sentimiento de irritación no había despegado (como lo haría a partir de 2006) cuando el análisis público del gobierno de Bush empezaba a arrojar balances negativos en prácticamente todos los ámbitos de la acción gubernamental.

Como podemos apreciar en la mencionada tabla, el porcentaje de personas enojadas no volverá ya a niveles de un dígito. Y un porcentaje cercano a un cuarto de la población mantendrá esta actitud. El porcentaje de frustrados se moverá por encima de los 50 puntos de manera consistente, con lo cual tenemos a prácticamente tres cuartas partes de la población americana que se mueve entre la rabia y la frustración contra su gobierno. Y en franco contraste, una minoría de solo dos de cada 10 se muestran contentos. En otras palabras, la confianza en el gobierno refleja niveles extraordinariamente bajos. Esa población está predispuesta a consumir información que reafirme sus posturas.

Es interesante ver en perspectiva histórica el movimiento que tiene esta variable en la opinión americana. Lejos, muy lejos, quedan los cerca de $80 \%$ que a finales de la década de los 50 manifestaban confianza en su gobierno. Durante los años 60 la caída en el indicador fue constante y particularmente pronunciada hasta la década de los 80 en la que Reagan consiguió llevar la tasa de confianza a niveles superiores al 45\%. En los 90 el indicador volvería a caer a niveles muy similares a los que hoy se observan, pero, como se aprecia en la distribución de puntos y como ya señalábamos antes, 2001 le dio un nuevo aire al gobierno y una renta política que George Bush dilapidó. La polarización generada por la elección de Obama nunca superó la desconfianza y el índice nunca más volverá a repuntar. Dicho de otra manera, la confianza del gobierno no ha dejado de decrecer en los últimos 15 años. Eso explica, a mi juicio, porque un individuo como Trump pudo conectar con un segmento del electorado que sentía una enorme frustración con la acción gubernamental de Obama, pero que no tenía confianza en los políticos tradicionales del republicanismo que, como pudimos observar, 
perdieron buena parte de su crédito cuando ejercieron el gobierno bajo la presidencia de Bush.

Figura 9: Confianza en el gobierno (1958-2019)

\section{Public trust in the federal government remains at historic low}

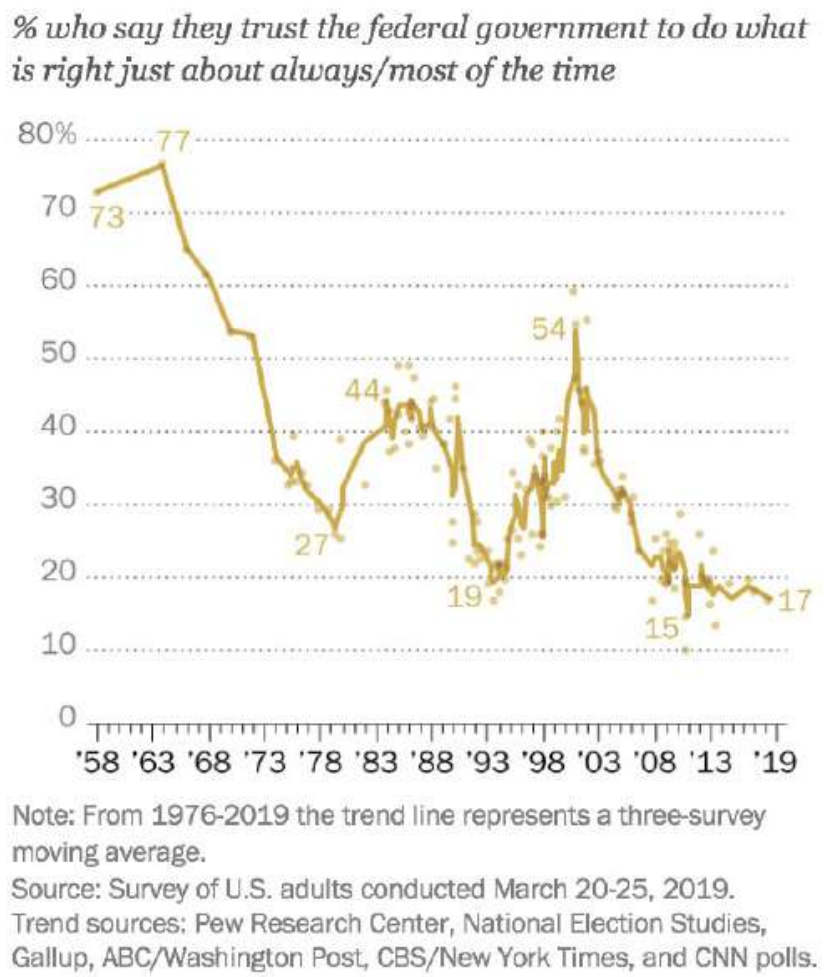

PEW RESEARCH CENTER

Fuente: Pew Research Center, May, 2017, "Public Trust in Government Remains Near Historic Lows as Partisan Attitudes Shift”.

\section{Diferentes fuentes, diferentes visiones. Lecturas alternativas}

En este contexto de atomización de la agenda pública, polarización y desconfianza, vale la pena revisar las fuentes que nutren de información a ese ciudadano irritado y desconfiado. Han corrido ríos de tinta sobre las páginas que consultaron los partidarios de Trump para informarse del proceso electoral. ¿Cuáles eran los medios a los que acudían para formarse un criterio? Sorprende, por ejemplo, que su animadversión a los tratados de libre comercio no fue compartida por los medios más cercanos a la derecha económica (The Wall Street Journal, por ejemplo) ni por el establishment tradicional de los medios cercanos a la órbita republicana. Nosotros tomaremos como punto de referencia la encuesta publicada por el Pew Research Center que se realizó entre finales de noviembre y principios de diciembre de 2016 con un panel representativo de las opiniones de los americanos.

La relevancia que Internet y las redes sociales tuvieron en esta elección es muy grande, como quedó establecido en páginas precedentes. Sitios de Internet como Breitbart o BuzzFeed cumplieron una función estratégica (Woodward, 2018) en el posicionamiento de las ideas del universo trumpista y configuraron la plataforma ideológica que resultó finalmente triunfadora en las elecciones de noviembre del 2016. Sin desconocer el peso específico que hoy las redes sociales y el ciberespacio juegan en la distribución de información y en la articulación de opiniones, conviene señalar que la televisión siguió siendo el medio más importante para obtener información sobre el proceso político. Como puede verse en el siguiente gráfico, la cadena más mencionada (como principal fuente de información de las campañas del 2016 por todos los votantes) fue Fox News. Dos de cada 10 americanos utilizaron esa cadena conservadora para obtener su información. En segundo lugar, viene CNN con un distante 13\% y después Facebook, plataforma que, como hemos visto, generó un ambiente incierto por la dispersión de noticias falsas. Prácticamente la mitad de la población se informó por estas tres vías 
Figura 10: Los votantes y su fuente de información

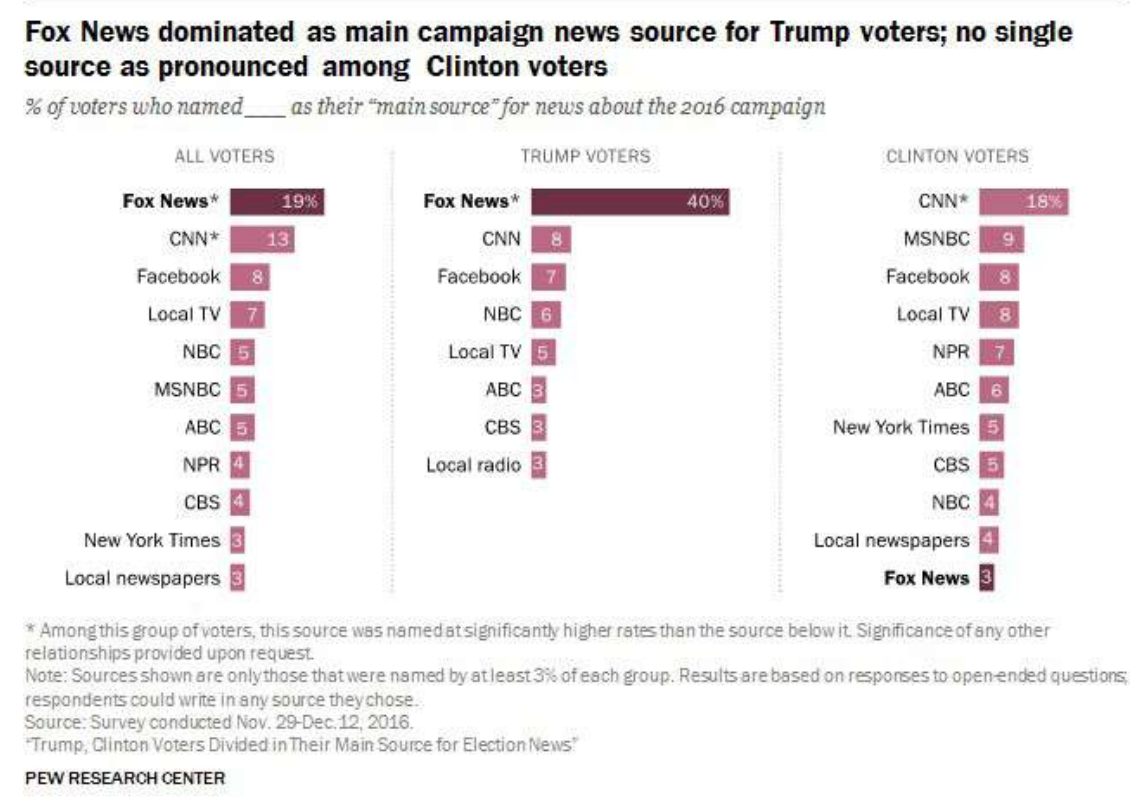

Fuente: Pew Research Center, January, 2017, “Trump, Clinton Voters Divided in Their Main Source for Election News”.

Fox News es una cadena que ofrece un encuadre conservador con un elevado nivel de editorialización de la agenda informativa. El foco está puesto en agradar los oídos de audiencias más conservadoras (Erikson, 2015, p-239) predispuestas a buscar eso que habíamos llamado ya la conformidad acústica. En esa cadena se difundió, por ejemplo, con enorme frecuencia que Obama no era un ciudadano en los Estados Unidos y es fácil escuchar también en su programación que la de México es una frontera porosa y peligrosa, que representa una amenaza similar a Afganistán o Pakistán y, por tanto, una defensa constante del argumento del país con un muro fronterizo.

Su modelo de negocios en el ámbito informativo tiene un componente particular que es preciso conocer con más detalle (Cassino, 2016). Para los efectos de este texto, baste decir que si es un buen negocio desplazar a la verdad (o la objetividad periodística) a un segundo plano, no hay demasiada resistencia en hacerlo si a quien se afecta es a un enemigo ideológico. Son medios altamente partidistas con un nivel de arbitrariedad superlativo y no sorprende que el $40 \%$ de los votantes del neoyorquino eligieran Fox News como su principal fuente de abastecimiento noticioso. Sólo el $8 \%$ refería ver habitualmente CNN y el 7\% consignaba informarse a través de Facebook. La prensa seria, esa que publicó de manera casi unánime editoriales críticas de lo que la plataforma de Trump y su programa político suponían, simple y llanamente no fue leída por sus votantes. Si miramos los detalles de las prácticas informativas de los electores de Hillary Clinton, veremos que el New York Times, por ejemplo, era consultado por el 5\%. No nos detendremos en la distribución de cada uno de los medios consignada en la tabla, pero subrayamos la relevancia que la cadena Fox tuvo en la difusión y la construcción del fenómeno Trump. Aún como presidente Trump, insiste en denostar a todas aquellas cadenas que no comparten su visión y excluye sistemáticamente a Fox de esa categoría, es más, en su cuenta de twitter muchas veces festeja los elevados niveles de audiencia de Fox como si fuese su publirrelacionista. Una simbiosis mutuamente benéfica.

\section{Colofón}

Con el triunfo de Donald Trump el término "fake news" adquirió una connotación de arma arrojadiza en contra de sus críticos. Hoy esa creciente dificultad para tener una deliberación saludable en donde la verdad sea el principal referente es una de las principales amenazas a la integridad de la deliberación democrática. La utilización sistemática de elementos falsos forma parte de una estrategia política americana y amenaza con mover la verdad a un relativismo político extremo que rompe la posibilidad de organizar debates en la que los adversarios se reconozcan mutuamente como opciones válidas y legítimas. Si en años anteriores el concepto se refería a portales de noticias poco rigurosos que fabricaban noticias sensacionalistas, el actual presidente se ha encargado de etiquetar a la prensa seria y a los medios electrónicos bajo esta engañosa categoría. Uno de los contrapesos más eficaces se ha debilitado. 
Es legítimo preguntarse a estas alturas si la apuesta de Trump por hostigar a los medios tradicionales es un daño irreversible para la integridad del sistema democrático, pues una prensa libre y vigorosa es fundamental para alimentar la deliberación pública y establecer una supervisión del ejercicio del poder. Esta inquietud admite dos lecturas. La primera es que el conjunto de instituciones de ese país es lo suficientemente sólido para resistir una agresiva tormenta verbal del inquilino de la Casa Blanca. Algunos actos arbitrarios, como excluir a representantes de ciertos medios de determinados eventos o agresivas interrupciones de entrevistas a conductores críticos (Dickerson, 2017) o incluso la amenaza de cancelar las conferencias de prensa (@realDonaldTrump, mayo, 2017) pueden ser catalogados como un intento de coartar la libertad de los medios y su función de control democrático. Los medios americanos enfrentan una grave crisis en su modelo de negocios tradicional, pero conservan una fortaleza considerable para resistir una presión política de la Casa Blanca, especialmente si consiguen mantener una unidad de propósito que el propio Trump facilita al criticarlos en bloque.

La segunda es que la hostilidad del presidente a la crítica puede minar, en determinados sectores, la cultura del escrutinio y la desconfianza que hoy suscitan los medios tradicionales en amplios sectores de la población. En un ambiente social que combina atomización de la agenda con radicalización creciente de la población, la democracia americana puede caminar por una senda de populismo nacionalista que no solamente le quite su ejemplaridad, como lo hacía notar Diamond (2016) en un texto reciente, sino que cada vez menos americanos consideren que el opositor no es un actor moralmente válido con el que se dialoga o discute, sino un enemigo de los valores fundantes y los medios tradicionales, como dijo Kellyanne Conway, un enemigo del pueblo. No puede haber democracia sin pueblo informado y sin una prensa libre, por tanto, el trumpismo representa una amenaza seria a la integridad de la democracia norteamericana.

\section{Referencias}

1. Benton, J. (2016, Nov, 6). The forces that drove this election's media failure are likely to get worse. Nieman Lab. Dipsonible en: http://www.niemanlab.org/2016/11/the-forces-that-drove-this-elections-mediafailure-are-likely-to-get-worse/

2. Bobbio, N. (2013) Democracia y secreto. México: FCE.

3. Cassino, D. (2016) Fox News and American Politics: How One Channel Shapes American Politics and society. US. Routledge.

4. $\quad$ Castells, M. (2012). Redes de indignación y esperanza. Madrid. Alianza.

5. Cramer, K. (2016). The Politics of Resentment: Rural Consciousness in Wisconsin and the Rise of Scott Walker. US. University of Chicago Press.

6. Diamond, L. (July/August 2016). How Washington Can Reverse the Tide. En: Foreign Affairs.

7. Dickerson, J. (May 1, 2017). President Trump's interview in the Oval Office: Full Transcript. CBS News.

8. Donald J Trump: @newtgingrich just stated that there has been no president since Abraham Lincoln who has been treated worse or more unfairly by the media than your favorite President, me! At the same time there has been no president who has accomplished more in his first two years in office! Disponible en: https://twitter.com/realDonaldTrump/status/1086597047229300737.

9. Donald J. Trump: ...Maybe the best thing to do would be to cancel all future "press briefings" and hand out written responses for the sake of accuracy??? Disponible en: https://twitter.com/realDonaldTrump/ status/863002719400976384.

10. Drèze, J. y Sen, A. (2013). Una gloria incierta. India y sus contradicciones. Madrid: Taurus. 2013. P. 271 y 55. 
11. Erikson, R. and Tedin, K. (2015). American public opinion: its origins content and impact. US. Routledge. P. 239.

12. Fogel, J. y Patiño, B. (2007). La prensa sin Gutenberg. Madrid. Punto de lectura.

13. Fukuyama, F. (2018). Identity: The Demand for Dignity and the Politics of Resentment. NY. Farrar, Strauss and Giroux.

14. Ginsburg, T. and Aziz Z. H. (2018). How to save a constitutional democracy. US. University of Chicago Press.

15. Greenblat, S. (2018). Tyrant. Shakespeare on politics. US. Norton and Company.

16. Gutmann, A. \& Thompson, D. (2004). Why Deliberative Democracy? US: Princeton. University Press.

17. Krugman, P. (19 de septiembre de 2016). Los medios se 'hacen de la vista gorda' con fallas de Trump. El Financiero.

18. Latest false fact-checks on Donald Trump. Politifact.com Disponible en: http://www.politifact.com/ personalities/donald-trump/statements/byruling/false/

19. Levitsky, S. y Ziblatt, D. (2018). ¿Cómo mueren las democracias? México: Ariel.

20. Neuman, R, Bimber, B. y Hindman, M. (2011) “The internet and four dimension of citizenship" en: Shapiro, R. y Jacobs, L. The Oxford Handbook of American Public Opinion and the Media. US. Oxford University Press.

21. Poniewozik, J. (2018). Audience of one: Donald Trump, television and the fracturing of America. US. Liveright.

22. Popper, K. (1998) La televisión es mala maestra. México. Fondo de Cultura Económica.

23. Protess, D. y McCombs, M. (eds) (1991). Agenda Setting: Readings on Media, Public Opinion, and Policymaking. NY. Routledge.

24. Real Academia Española (2017). Posverdad. Diccionario de la lengua española (23a ed). Consultado en: https://dle.rae.es/posverdad.

25. Rivera B. (2012, 19 octubre). ¿Qué es transmedia y storytelling? Disponible en: https://agencia.best/blog/ transmedia-y-storytelling/.

26. Rose, J. (April 25, 2018). Why Trump is winning and the press is losing. NYR Daily. Disponible en: https:// www.nybooks.com/daily/2018/04/25/why-trump-is-winning-and-the-press-is-losing/.

27. Rubio, D. (2017, marzo). La política de la posverdad. En: Política Exterior. No. 176. P. 58-67.

28. Sartori, G (2003). ¿Qué es la democracia? México: Taurus.

29. Sartori, G. (1998). Homo Videns. La sociedad teledirigida. Madrid. Taurus.

30. Sartori, G. (2003) Videopolítica. Medios, información y democracia de sondeo. México. FCE/ITESM.

31. Singer, P. (2004) El presidente del bien y el mal. Las contradicciones éticas de George Bush. Barcelona Tusquets.

32. Taibbi, M. (2019). Hate Inc.: Why Today's Media Makes Us Despise One Another. US. OR Books. 2019. 
33. The Washington Post. (November 9, 2016). President Trump.

34. TIME (3 de abril 2017). Is truth dead? (Portada).

35. Trejo Delarbre, R. (2015). Alegato por la deliberación pública. México: Cal y Arena.

36. Trump, D. (Septiembre, 2019). Discurso del Presidente Trump Ante la 74 a Sesión de la Asamblea General de las Naciones Unidas. Nueva York. Sede de las Naciones Unidas.

37. Trust Barometer. Global Report (2019). Edelman. Disponible en: https://www.edelman.com/ sites/g/files/aatuss191/files/2019-03/2019 Edelman Trust Barometer Global Report.pdf?utm $\underline{\text { source }=\text { website\&utm medium }=\text { global report\&utm campaign }=\text { downloads }}$

38. Urbinati, N. (2019). Me the people. How populism transforms democracy. US. Cambridge Mass. Harvard University Press.

39. Wolfe, A. (2018). The Politics of Petulance: America in an Age of Immaturity. US. University of Chicago Press.

40. Woodward, B. (2018). Miedo. Trump en la Casa Blanca. México. Roca Editorial. 